\title{
THE FOUR CASE STUDIES ON THE EFFECTS OF CORPORATE SOCIAL RESPONSIBILITY ON WATER POLLUTION: DO CONFLICTS AFFECT A COMPANY'S CSR POLICY?
}

\author{
Ainura Sattarkhanova \\ School of Business \\ Nanjing University of Information Science and Technology, Nanjing, China
}

\begin{abstract}
As the world pays more attention to environmental sustainability, organizations need to pay more attention to solving the global water crisis and minimizing its impact on themselves and the planet. Businesses today have a huge impact on the environment and make excessive use of available natural resources and emit harmful pollutants. In order to obtain specific information about the company's water resources strategy and practices, an exploratory analysis was carried out on five multinational companies. This article presents four case studies of the Corporate Social Responsibility Guidelines from Coca-Cola, Mondelēz International, Nestlé and PepsiCo. These multinational companies are involved in environmental conflicts. The main focus of this article is to examine the role of business today in freshwater. In summary, four case studies from CocaCola, Mondelēz International, Nestlé and PepsiCo show that multinational corporations changed their corporate social responsibility and reporting policies after the conflict. These companies resolve these conflicts publicly through the media or in their annual or sustainability reports, thereby making these conflicts transparent.
\end{abstract}

Keywords - Coca-Cola, Corporate Social Responsibility, Mondelēz International, Nestlé, PepsiCo, and Water Pollution

\section{INTRODUCTION}

All life needs water. It is the most precious resource in the world. Freshwater habitats such as lakes, rivers, streams, wetlands and aquifers are an incredible part of the world's biodiversity: more than $10 \%$ of all known animals and more than $50 \%$ of all known fish. Although water plays a huge role in humans and nature, it is a surprisingly limited resource. From food and energy security to human and environmental health, water can help improve social well-being and inclusive growth that affect billions of people [1]. By 2025, nearly 1.8 billion people living in different parts of the world will face absolute water shortages [2]. Safe drinking water and sanitation are regarded as basic human rights because they are essential for maintaining a healthy livelihood and for maintaining the dignity of all people. Therefore, humancentered water and sanitation services and reasonable and sustainable water resources management are measures for sustainable development and the full exercise of human rights in water and sanitation facilities and various other rights. Human rights are inseparable from the management of water resources and the entire environment. Insufficient access to water and sanitation facilities is related to social unrest, conflict and even violence, and ultimately to the increasing trend of displacement and population migration [3].

Traditionally, regional water management, the access and use of water by individuals and companies are regarded as public affairs and therefore are usually managed by local authorities [4]. Therefore, the industry is the main consumer of water and is regarded as an important contributor to water pollution [5]. A question arises: What if a company in a particular area uses fresh water and fresh water consumption threatens an individual's access to water? As part of the answer, some people think water management requires a joint approach by the government and enterprises [6]. According to Break Free from Plastic [7], the top ten polluters in the world in 2020 are: Coca-Cola, PepsiCo, Nestlé, Unilever, Mondelēz International, Mars, Procter \& Gamble, Philip Morris International, Colgate-Palmolive, and Perfetti Van Melle. Only the three largest companies (Coca-Cola, Pepsi and Nestlé) account for $14 \%$ of global branded plastic pollution.

The main objective is to explore the role of the chosen five companies (Coca-Cola, Mondelēz International, Nestlé and PepsiCo) about freshwater. Because business leaders make decisions every day that can affect water, it is important to identify where such decisions can also improve the water sector. Companies themselves have started recognizing that they can have a positive impact on preserving water resources and in granting people access to water. The research addresses how companies can bear responsibility for their impact on 


\section{International Journal of Engineering Applied Sciences and Technology, 2021 \\ Vol. 5, Issue 9, ISSN No. 2455-2143, Pages 30-43 \\ Published Online January 2021 in IJEAST (http://www.ijeast.com)}

water resources as part of corporate social responsibility (CSR). Sub questions explored in this article are: What are the best practices in this field? Do conflicts affect a company's CSR policy? Thus, it is crucial to explore what companies can do from a corporate social responsibility (CSR) standpoint to address the global water crisis, and minimize their impact on themselves and the planet.

\section{METHODOLOGY}

The author selected a group of multinational companies that do business around the world, including Coca-Cola, Mondelēz International, Nestlé and PepsiCo. These four companies lag behind among the world's most polluting countries, including the major single-use plastic container manufacturers and producers, which are the largest contributors to water pollution. These four case studies are compared by examining the CSR conflicts that every multinational company faces, which to some extent become the turning point of these multinational companies' CSR policies.

The reaction of each multinational company to the conflict is analyzed, how the company resolves the conflict and whether the company has implemented a specific CSR policy with measurable goals to manage the conflict. The research is based on desk research. The companies involved in water disputes are the main consumers of water, namely agricultural, beverage, food and mining companies. This article uses publicly available information on company websites, online newspapers, and reports from non-governmental organizations (NGOs), as well as in academic journals and books. The parent companies of multinational companies are located in different countries: Switzerland and the USA. This means that different legal systems and jurisdictions apply. In addition to environmental data and public reports, learning from the experiences of other organizations can also improve water management plans.

\subsection{Coca-Cola's Profile}

The Coca-Cola Company was founded as a local soda producer in Atlanta, Georgia, USA in 1886 and sold about nine beverages daily [8]. In the 1920s, the company began to expand internationally, initially selling its products in the Caribbean and Canadian markets, then moving to Asia, Europe, South America and the Soviet Union for decades. The company operates a wide variety of products in 200 countries, including a staggering 500 brands and more than 3,300 beverages. The company believes the Coca-Cola name is worth billions of dollars in itself. In 2005 it became the world's largest manufacturer, distributor and marketer of soft drinks and syrups [8].

\subsubsection{Coca-Cola's CSR Policies and Reporting}

In 2007, Coca-Cola launched Live Positively, a framework for sustainable development from production to packaging to sales, embedded in the system. The company's corporate social responsibility guideline "Carry out activities actively" defines seven core areas in which the company has set measurable goals to improve the company's sustainable development practices [8]. Core areas are beverage wellbeing, active and healthy living, communities, energy and climate, sustainable packaging, water management and jobs.

Coca-Cola formulated the "Code of Business Conduct" to provide employees with guidelines on competition issues and anti-corruption measures. The company has adopted global CSR guidelines such as the Global Compact and the Ruggie' Protection, Respect and Remediation Framework (Ruggie's Framework). However, these guidelines do not appear to be built into the business guidelines. However, these CSR plans have been incorporated into other company activities or policies. For example, the company's annual sustainability review refers to the United Nations Global Compact principles and the company's Human Rights Statement [9] uses Ruggie's framework. In 2018, the company announced a clear and simple goal, the World No Waste Initiative: by 2030, bottles or cans should be collected for sale and recycled.

Compared to the benchmark of 2010, the water efficiency of production companies increased by $25 \%$ by 2020 . In addition, the Coca-Cola Company and the WWF formed a partnership in 2007 [8]. Their main goal is to improve understanding of water catchment areas and water cycles to improve CocaCola's water use, work with local communities around the world, and develop a common framework to protect water sources. That same year, the company finally became a member of the CEO Water Mandate, which is the publicprivate program that helps the company formulate, implement and disclose policies and practices related to the sustainability of water.

Every year Coca-Cola publishes a report by its directors called "The Coca-Cola Company Annual Report". The last report was published in 2020, including the company's activities in 2019 [9]. There is a Corporate Social Responsibility section in this report that briefly introduces the community development and water conservation measures the company has formulated. Since 2001, Coca-Cola has published a separate corporate social responsibility report every year called the Coca-Cola Company Sustainability Report [10]. This review provides a "medium guarantee" of the reliability of the information reported by Coca-Cola. Both reports (annual company report and sustainability report) are based on the GRI G3 guidelines that the company adopted in 2001.

\subsubsection{Coca-Cola's Conflicts}

The Center for Science and Environment (CSE), a nongovernmental organization in India, published a report in 2003 [10]. The report provides evidence that the pesticide levels of 


\section{International Journal of Engineering Applied Sciences and Technology, 2021 \\ Vol. 5, Issue 9, ISSN No. 2455-2143, Pages 30-43 \\ Published Online January 2021 in IJEAST (http://www.ijeast.com)}

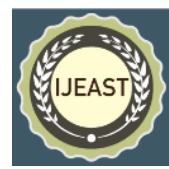

more than a dozen Coca-Cola and Pepsi drinks sold in India exceed European standards. With this evidence, CSE calls on the Indian government to implement legally effective water standards. The report has received a lot of public and media attention and has an almost direct impact on Coca-Cola's revenues. The NGO's main allegations against Coca-Cola were that the organization sold products that contained unacceptable amounts of pesticides, extracted large amounts of groundwater and contaminated water sources [11].

\subsubsection{The presence of pesticides}

The Government of India has conducted various investigations into allegations that Coca-Cola beverages contain large amounts of pesticide residues. The government set up a joint committee to conduct its own tests on beverages. The test also found that pesticides do not meet European standards but are still considered safe by local standards. Hence the conclusion is that Coca-Cola did not violate any national law. However, the Indian government recognizes the need to set adequate and enforceable standards for carbonated beverages.

After nearly three years of uninterrupted allegations, CSE issued a second test for Coca-Cola drinks in 2006, and pesticide residues are also high (24 times higher than the EU standard proposed by the Bureau of Standards of India) [11]. The CSE issued the test to prove nothing has changed, claiming that the stricter standards for carbonated and other beverages on the committee had been lost or blocked by strong government interests. Finally, in 2008, an independent study by the Energy and Resources Institute (TERI) put an end to long-standing allegations that the water used in Coca-Cola in India did not contain pesticides. However, since the institute has not tested the end product, other ingredients may also contain pesticides [9].

\subsubsection{Water Pollution and the Over-Extraction of Groundwater}

Coca-Cola is also accused of causing water shortages in areas such as the Plachimada community in Kerala, southern India. Groundwater and soil are so polluted that Indian health authorities consider it necessary to put up signs around wells and hand pumps to inform communities that the water is not safe for human consumption. There have been complaints and protests from the local community that the factory was using too much groundwater, exhausting and polluting local wells. Panchayat is responsible for these protests. A specialty of the Indian government is Panchayat (Local Committee), which is responsible for regulating the use of local resources, including water [11].

The company set up a production department in Plachimada in 2000. Locals said they suffered from water shortages shortly after the operation began. The state government filed a lawsuit against Coca-Cola in 2003, the Kerala Supreme Court banned Coca-Cola from overusing groundwater [9]. By 2004, the company had ceased production and tried to renew its operating license. Coca-Cola believes that reduced rainfall is the primary driver behind the blueprint for the situation in the region. After a lengthy legal process and continuous demonstrations, the company successfully received a renewal permit to resume operations [11]. When the Kerala government banned the manufacture and sale of Coca-Cola products in Kerala in 2006, Coca-Cola successfully resumed operations, which was unsafe due to its high pesticide content. However, the ban did not last long. Later that year, the Indian High Court overturned the Kerala court's decision.

Recently, in March 2010, a state government team recommended that Coca-Cola's subsidiary in India be fined \$ 47 million for damage to water and soil in Kerala. In addition, a special committee was set up to examine the opinions of community members affected by water pollution. The brand suffered a huge loss of consumer trust and reputation in India and abroad. This controversial conflict in India has also caught the attention of American consumers. Ten American universities temporarily stopped selling Coca-Cola products in their campus facilities after a series of demonstrations by students who had joined two militant organizations in the United States [12].

\subsubsection{Coca-Cola's CSR Policies Post-Conflicts}

Two years before the 2003 water conflict in India, Coca-Cola adopted the GRI guidelines and started reporting on sustainability. By 2003 the company had already experienced some CSR conflicts in other parts of the world (Coca-Cola, 2020). However, none of them caused serious consequences for consumers and the general public to lose confidence in its products. According to Pirson and Malhotra [13], the main reason this controversy ended so badly for Coca-Cola is the response to the problem. Coca-Cola denies that its drinks contain high pesticides and that its water resources have been overfished and polluted. By rejecting all claims and proving their integrity, Coca-Cola showed no concern about the situation and failed to regain consumer confidence.

Although Coca-Cola still denies most of the allegations, the loss of reputation caused by the Indian dispute forced CocaCola to limit the damage. These measures initially included a declaration confirming the integrity of Coca-Cola. For example, Coca-Cola specifically introduced a page in the Corporate Responsibility Review 2006 to resolve this dispute [11]. The statement mainly contains information supporting its best practices and the water management of its activities in India. However, the explanation barely addressed the losses caused by the drop in sales and the increase in investments. Coca-Cola gradually changed its strategy, including mitigation measures aimed at the grievances of the Indian community. 


\section{International Journal of Engineering Applied Sciences and Technology, 2021 \\ Vol. 5, Issue 9, ISSN No. 2455-2143, Pages 30-43 \\ Published Online January 2021 in IJEAST (http://www.ijeast.com)}

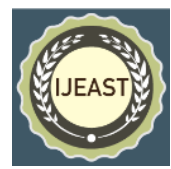

In 2008 the company published its first environmental performance report on Indian activities, which covered activities from 2004 to 2007 [8]. The Coca-Cola India Foundation, Anandana, was also created to work with local communities and NGOs to solve local water issues. However, Coca-Cola's most important strategic change could be the launch of various municipal water projects in India. The rainwater harvesting project is an example. Coca-Cola's activities work with the Central Groundwater Authority, the State Groundwater Commission, NGOs and communities to solve water scarcity and falling water table problems through rainwater harvesting technology in 17 Indian states. These technologies mainly include collecting and storing rainwater while preventing evaporation and runoff of rainwater for effective use and protection. The idea is to collect a lot of high-quality water that could have been wasted. By recirculating the water used in Indian operations back into the ecosystem through water use, the company expects the project to turn the company into a "net-zero" user of groundwater by 2009. In the 2012 Water Management and Supplementary Report, Coca-Cola-Cola stated that its Indian operations have "achieved a comprehensive balance between groundwater for beverage production and groundwater replenishment for nature and communities that exceeds global goals" [14].

It appears that the Indian dispute is a learning experience from the company that has inspired the company to adopt a more proactive corporate social responsibility policy on a global scale with an emphasis on water resource management. To meet these commitments, Coca-Cola has set three measurable goals:

(1) Improve water efficiency. In 2017, water efficiency improved for 15 consecutive years, which is $2.55 \%$ more than 2016 and 15\% more than 2010. Since Coca-Cola reported efficiency improvements in the global system in 2004, water efficiency has also increased by $29.3 \%$ [9]. Their system-wide water efficiency has improved for 15 consecutive years. When they started this journey in 2004, they used 2.7 liters of water to make 1 liter of product. Today they use 1.92 liters of water to produce 1 liter of product and are working to reduce it to 1.7 liters of water per liter of product by 2020 (a 25\% increase).

(2) Make $100 \%$ of the world's packaging recyclable by 2025 and use at least $50 \%$ of the recyclable materials in packaging by 2030 [10]. In the entire value chain, packaging accounts for $25 \%$ to $30 \%$ of their carbon footprint [14]. They believe that a circular economy solution that works for the local realm by converting old packaging into new packaging can reduce the climatic footprint of their packaging and keep plastic products out of the natural environment. Sixteen markets offer drinks in $100 \%$ recycled PET (rPET) bottles and there will be more to come. Water brands in Austria, Belgium, Ireland,
Peru, the Philippines, Switzerland, South Africa and Uruguay are now using fully recycled plastic to make water bottles. As of late 2019, seven out of ten bottles in Australia have been made entirely from recycled plastic. Sprite packaging has shifted from green bottles to transparent bottles in several markets, making it more valuable by improving the efficiency of the recycling flow. From 2020 all plastic bottles in Sweden used 100\% rPET, avoiding 3,500 tons of fresh plastic and reducing emissions by $25 \%$ [15].

\subsection{PepsiCo’ Profile}

Caleb Bradham founded PepsiCo in New Bern, North Carolina in 1898. PepsiCo products are enjoyed more than 1 billion times a day by consumers in more than 200 countries and regions worldwide. Pepsi's product portfolio includes various delicious foods and beverages, including 23 brands with estimated annual retail sales of more than $\$ 1$ billion [16]. PepsiCo is one of the world's leading food and beverage companies, with net income of more than \$ 67 billion in 2019 from a complementary food and beverage portfolio that includes Frito-Lay, Gatorade, Pepsi, Quaker, and Tropicana, as well as diversified and popular brands belong. In 1965, Donald Kendall, CEO of PepsiCo and Herman Lay, CEO of Frito-Lay, recognized what they called "Heavenly Marriage" as a company with perfect hearty snacks and the best in the world [16].

\subsubsection{PepsiCo's CSR Policies and Reporting}

Since the inception of the Pepsi-Cola Sustainable Development Plan, solving safe drinking water has always been a top priority for Pepsi-Cola. In 2009, PepsiCola was one of the first multinational companies to make a public commitment to respect water rights in their global activities [17]. This commitment stems in part from shareholder resolutions and collaboration with NorthStar Asset Management that the company must take active steps to ensure that its facilities have the ability of a community to receive decent and clean water and to provide those communities with access to shared water procure, not impair, play an important role in water abstraction. In addition, PepsiCo also works with nongovernmental organizations such as the Safe Water Network, Water.org, WaterAid, the China Women's Development Foundation, the Inter-American Development Bank, the Nature Conservation Association and the World Bank 2030 Water Resources Group [7].

The company values working with other stakeholders and is actively involved in creating and promoting precompetitive collaboration to improve water safety. Stakeholders include peer companies, nonprofits, and industry associations. For example, like other companies, 


\section{International Journal of Engineering Applied Sciences and Technology, 2021 \\ Vol. 5, Issue 9, ISSN No. 2455-2143, Pages 30-43 \\ Published Online January 2021 in IJEAST (http://www.ijeast.com)}

Pepsico and Walmart are forming members of the Midwest Row Crop Cooperation (MRCC). MRCC is a diversified alliance of industrial and nonprofit organizations dedicated to improving the safety of agricultural solutions to protect air and water quality and improve soil health. In another example, in 2018 PepsiCo granted full access to the Sustainable Agriculture Initiative (SFP) toolkit through the SAI platform [18]. The SFP Toolkit consists of detailed training materials, workshop activities, guides, and exercises designed to help farmers adopt more sustainable farming practices. By sharing this toolkit, the SAI Platform can increase the coverage and adoption rate of its Farm Sustainability Assessment Program. One measure of success is the large-scale adoption of sustainable agricultural practices. Therefore, PepsiCo's goal is to provide a wide variety of foods and beverages, from snacks to nutritious diets, finding innovative ways to reduce environmental impact and operating costs, creating and respecting a safe and inclusive workplace for employees worldwide.

\subsubsection{PepsiCo's Conflicts}

There is some conflict between the local communities in India and the beverage manufacturers who extract the water. Pepsi's water use caused controversy in India in the early and mid-2000s, partly due to PepsiCo's alleged impact on water use in a country where water shortages persisted for a long time. In this case, Pepsi-Cola was viewed by Indian environmental groups as a company that diverted water to produce non-essential goods, making it a target of critics at the time.

As a result, Pepsi-Cola launched a statewide plan in 2003 to achieve a "positive water balance" in India by 2009. In 2007, Indra Nooyi, CEO of Pepsi-Cola, traveled to India to discuss the country's water usage habits, and prompted former critic Sunita Narain, director of the Center for Science and the Environment (CSE), to point out that Pepsi "is now closed." seems to be "doing some serious water matters." According to the company's 2009 Corporate Citizenship Report and media reports at the time, the company refilled nearly 6 billion liters of water in India, exceeding the total water withdrawal at the Indian Pepsi-Cola facility by about 5 billion liters [19].

\subsubsection{The Over-Extraction of Groundwater}

In 1989 Pepsi-Cola set up a business unit in India. The company is now one of the largest consumer goods companies in India. PepsiCo currently employs 150,000 people in India. The company has more than 36 bottling plants, including 13 companies and 23 companies with franchise rights. In 2003, PepsiCo had problems with groundwater in India [18]. PepsiCo uses groundwater in
India to make soda water. The main component of soft drinks is water. It makes up almost $90 \%$ of the content of soft drinks. The Center for Science and Environment found that the toxin content of Pepsi beverages is usually above the European limit. CSE found that Pepsi-Cola soft drinks made in India had residual pesticides levels 36 times what EU regulations allow. CSE tested the same product in the US and found no such residue.

Groundwater is the main water source for $90 \%$ of rural areas and $50 \%$ of urban customers in India, and all parts of the country can be polluted. The test results prompted the government to adopt the EU standards for mineral water. The village government of Pudussery, a rural community in the Palghat district of Kerala, said last week it revoked the water permit for the Pepsi-Cola bottling plant because it depleted the community's groundwater and caused a shortage. The license does not expire until 2005. The area was arid due to the recent drought. Locals believed that Pepsi-Cola was overloading water resources, which made the shortage very serious.

\subsubsection{Pesticide Regulation in India}

PepsiCo's business in India suffered severe headwinds in 2003 and was boycotted again in 2006 when an environmental group in New Delhi alleged that Pepsi's pesticide levels, based on its research, exceeded proposed safety standards for soft drinks. Ingredients developed by the Bureau of Standards of India [20]. PepsiCo denied these allegations, and the Indian Ministry of Health also denied these allegations. The ensuing dispute led India to ban Pepsi-Cola soft drinks in Kerala in southwest India in 2006. However, a month later the Kerala High Court lifted the ban [7].

The Indian state of Kerala bans PepsiCo's manufacture and sale as people remain concerned about the lack of pesticides in rare beverages and the potential health effects on health [17]. PepsiCo continues to sell soft drinks with dangerously high levels of pesticides in India, even three years after the Indian government confirmed that these products were dangerous. In recent years, increasing pressure on water resources in the Indian states of Tamil Nadu and Kerala has led to local opposition to multinational companies and product boycotts. In 2018, Pepsi India had ten high water risk facilities, most of which rely on a single water source that relies on annual rainfall and becomes increasingly stressful in drought conditions.

In November 2010, the Supreme Court of India ruled that the Kerala government's criminal case against PepsiCo India was void because the drink met local standards at the indictment time. The court's decision found that the 


\section{International Journal of Engineering Applied Sciences and Technology, 2021 \\ Vol. 5, Issue 9, ISSN No. 2455-2143, Pages 30-43 \\ Published Online January 2021 in IJEAST (http://www.ijeast.com)}

\begin{abstract}
"percentage of pesticides" found in the beverages tested was within the permissible limits that were later prescribed for the product, as "at the time of the test there was no regulation for the adulteration of pesticides in cold beverages duration". According to a US State Department survey, PepsiCo was one of 12 multinational corporations to present the "Most Impressive Certificate for Corporate Social Responsibility in Emerging Markets" in 2010. Pepsi-Cola India is known for its water-saving and safety practices and results [17].
\end{abstract}

\subsubsection{PepsiCo's CSR Policies Post-Conflicts}

Water management has long been a top priority for Pepsi. They know that the ability to manage their water footprint is inseparable from the success of their business and the communities in which they operate. It was one of the first companies to recognize water as a human right. To meet these commitments, Pepsi-Cola has set five measurable goals:

(1) Increase in water use efficiency in direct agricultural supply chains with high water risk by $15 \%$ by 2025 [18]. In accordance with the 2025 Agenda for Sustainable Development, the company has set a global goal of increasing water use efficiency in areas of high-water risk in its direct agricultural supply chain by $15 \%$ by 2025 . The aim is to adopt the growers' irrigation habits in areas with high water risk. Their goal is to improve water use efficiency in areas of high water risk the most, as defined by the World Resources Institute's Aqueduct Tool. This mapping tool helps companies understand where and how global water risks are developing.

(2) Add $100 \%$ of the water used in the manufacturing process to [18]. They have set a goal of replenishing $100 \%$ of the water used in their production processes in high-water risk areas by 2025 and ensuring that replenishment occurs in the same watershed where extraction takes place. Resupply targets are specifically aimed at high water risk areas where they operate and are most in demand. In 2019, they updated their goals and committed to supplementing water consumption. In 2019, the company added more than 1.6 billion liters of water through global projects. To achieve the goal of replenishing water in the high-risk basins from which water is drawn, they limit the profit report cap to $100 \%$ for projects that achieve $100 \%$ of their basin goals. In 2019, they replenished $10 \%$ of the water used in the company's manufacturing facilities in high-risk pools. This is an increase $(8 \%)$ compared to the adjusted performance of 2018 [18].
(3) Adopt the standards of the Water Management Alliance as their tool for promoting water supply (PepsiCo, 2021). A positive impact on the water means an improvement in water security in the four walls and an improvement in the water security of the catchment area in which it is operated. They support existing collaborative efforts to manage water risks reduce water insecurity, and create new opportunities for collaboration if they deem it necessary. PepsiCo is a member of the Water Management Alliance (AWS). Their goal is to introduce AWS standards as advertising media in all facilities with high water risk by 2025 and ensure that fresh water resources in high water risk locations are available to all water stakeholders. In 2019 they started a pilot project to adopt the standard for systems with high water risk in South Africa, Pakistan, and Mexico and started the fourth pilot project in 2020 (Chadha, 2010). These pilots formed a cross-functional team of Pepsi-Cola employees and gathered to diagnose local water risks and the facility's chance to become a good water manager.

(4) Provide 25 million people with clean water by 2025 [18]. Water issues that will be considered in their strategy to meet long-term goals include water risk assessments for their manufacturing operations and agricultural supply chains. In 2016, they launched a "Targeted Performance" strategy that includes a proactive water impact strategy. Most goals have a target deadline of 2025. However, the strategy for achieving long-term business goals extends well beyond 2025 [18]. As an example of inclusion in the plan, the M\&A strategy includes requirements for assessing the water risk of M\&A activities. Because these locations are long-term Pepsi-Cola assets, the strategy aims to protect these assets from waterrelated risks during this time [18].

\subsection{Nestlé Profile}

Nestle S.A. with headquarters in Vevey, Switzerland, is the world's largest supplier of mineral water. Nestlé is a multinational company. The company was founded in 1869 by the pharmacist Henri Nestlé, who developed infant formula formulas for infants who could not breastfeed. Around the turn of the century, Nestlé merged with rival Anglo-Swiss Condensed Milk Company and began operating factories in the US and Europe to make powdered milk and other products. Nestlé is one of the top 10 best performing food and beverage companies globally, with total daily sales of more than $\$ 1.1$ billion. This industry accounts for $10 \%$ of the world economy. Nestlé itself admits that it is a "world food company" and has factories in almost every country in the world [21]. The company's food and beverage range include coffee, dairy, infant and adult nutrition, ice cream, soups and 


\section{International Journal of Engineering Applied Sciences and Technology, 2021 \\ Vol. 5, Issue 9, ISSN No. 2455-2143, Pages 30-43 \\ Published Online January 2021 in IJEAST (http://www.ijeast.com)}

broths, pasta, chocolate and candy, cereal breakfasts, pet care and bottled water.

\subsubsection{Nestlé's CSR Policies and Reporting}

To ensure that Nestlé's water efficiency continues to improve, all factories have adopted the "reduce, reuse and recycle" method. By the end of 2019, since 2010, the company's total water withdrawal per tonne of the product had been reduced by $31 \%$, with a total water withdrawal of 121 million cubic meters. To show respect for the environment and support for sustainable development, Nestlé formulated the "Nestlé Environmental Policy". This guideline is based on the content that was first published in 1991 and updated in 1999. This is Nestlé's long-term commitment to environmentally sound business practices around the world. In addition, the "Nestlé Water Policy" was first published in 2000 and has been updated in this document. It confirms the company's long-term commitment to the responsible water resources, which is part of Nestlé's broader commitment to sustainable development in general.

Responsible water management in Nestlé is based on a roadmap for sound water management. They implement AWS standards in multi-priority locations around the world. The Alliance for Water Stewardship (AWS) is a global water management system based on AWS standards. The standard is a framework for global users to understand their water consumption and its effects and coordinate and transparently implement sustainable water resource management in the catchment area (Nestlé, 2021). It can help them identify areas for improvement: providing factories, local catchment areas, areas throughout the agricultural supply chain, and water sources where communities exist. They have brought many benefits to the local Watershed and Nestlé communities.

For instance, Nestlé Pakistan has invested a lot of energy in water management and has received AWS certification at two locations including Sheikhpura and Islamabad. The local team works with partners on various projects including optimizing water consumption in production, providing clean drinking water for local communities and working with farmers in our supply chain. Currently they are working with farmers on 10,000 hectares to use rice fields instead of flood irrigation and to a lesser extent rice fields and corn irrigation. The annual water saving is estimated at 20 million cubic meters. The store supplies 60,000 people with clean and safe drinking water every day via six water supply stations [21]. Additionally, in California, all five bottling lines have passed AWS certification. The audit process during the certification period showed that we took measures between 2016 and 2017 to progressively monitor and optimize the water use of our facilities and to save more than 204 million liters of water [22]. The Cabazon facility is also the first site in North America to receive gold certification for its active contribution to local groundwater systems and water quality measures that meet best practice standards. It is important that the local stakeholders in the basin reaffirm the positive contribution of the Cabazon facility.

Nestlé believes that in order to be successful in the long term and to create value for shareholders, it must create value for society, that is, Creating Shared Value. Creating Shared Values has become an integral part of Nestlé's business. It is based on compliance with international laws, codes of conduct and corporate principles and focuses on environmental sustainability. The aim is to create new and greater value for society and shareholders in areas where the company can make the most impact (food, water and rural development).

\subsubsection{Nestlé's Conflicts}

Nestlé is currently implementing an ambitious and large-scale business strategy in Pakistan. The Pakistani market is one of the most promising market opportunities due to the large population and growing middle class who can afford soft drinks and bottled water. Nestlé stated that the Pakistani market has enormous growth potential. However, the widespread water scarcity in Pakistan has posed obvious challenges and led to ongoing conflicts between Nestlé over the company's massive water needs. Taking the economic environment into account, business interests and opportunities will conflict and lead to significant unethical behavior. The poor have paid a heavy price for economic development, of which they are not part, because Nestlé took its water and distributed it to higher-quality middle-class consumers.

\subsubsection{The Over-Extraction of Groundwater}

Nestlé's "Pure Life" bottled water label is big business in Pakistan, where inadequate drinking water is a serious problem and the company has a $50 \%$ market share. Nestlé's "Pure Life" products stimulate groundwater, thereby lowering the water table. If these causes deplete local water supplies, it can also endanger people's right to health. Insufficient water resources are the main cause of disease. When the existing water supply decreases, people have to rely on unsafe water sources. In addition to the indirect health effects, it has also been stated that Nestlé is constantly being accused that its bottled water, particularly Pure Life, does not meet national quality standards. Lack of data and ongoing disputes prevent accurate assessment of these allegations. However, it can be concluded that if Nestlé's "Pure Life" is not safe and is sold anyway, it directly violates people's water and health rights.

Nestlé's promise in Pakistan is still a long way off, however. The price for a 1.5-liter bottle of Nestlé "Pure Life" (and other brands) is 22 PKR (\$0.38). A family of four can take up this money. Given that the United Nations estimates that each person needs five liters of water a day, it would cost about 


\section{International Journal of Engineering Applied Sciences and Technology, 2021 \\ Vol. 5, Issue 9, ISSN No. 2455-2143, Pages 30-43 \\ Published Online January 2021 in IJEAST (http://www.ijeast.com)}

2,200 Pakistani rupees (\$ 38.60) per month to meet those needs with bottled water. When that number is multiplied by a family of four, the cost of bottled water exceeds the average monthly income. As a result, bottled water has no other choice for an inadequate water supply. If families use it as a substitute, they will put their families in debt or sacrifice other human rights satisfactions such as education, food, or shelter. The United Nations Development Program believes that bottled water is an expensive alternative that is unaffordable for the segment of the population hardest hit by the inadequate water supply.

For the vast majority of people who do not have access to safe drinking water, Nestlé's "Pure Life" in Pakistan is not an affordable alternative. On the contrary, the introduction of bottled water in Pakistan is an attempt at the culture of bottled water. In the culture of bottled water, water is a status symbol and a lifestyle of the wealthy. Allocating public services (such as water) along social status would be discrimination and therefore a violation of human rights. However, private companies can still define their market goals independently and only address certain groups of potential customers. However, Nestlé's market strategy goes against its commitment to human rights and sustainable development, which is vital from an ethical standpoint.

\subsubsection{Nestlé’s CSR Policies Post-Conflicts}

Water is essential to the operations of Nestlé and they recognize that they have a responsibility to use water as efficiently as possible. The company's focus on innovation depends on its purpose and commitment to creating shared value. To solve the water crisis and drinking water shortage of the Pakistani government:

(1) The Government of Pakistan should acknowledge the water crisis and start collecting sufficient data.

(2) Second, Nestlé is responsible for its commitment to human rights and sustainability. On the one hand, the quality standards should be effectively enforced. The lack of funds and the weak regulatory status of institutions such as PCRWR and PSQCA need to be addressed within government agencies and by civil society agencies. Cross-subsidizing the quality control plan (imposing a rate on each bottle) can be an opportunity to provide adequate funding. If Nestlé violates Pakistani law, it must face the consequences instead of using its "opportunity to obtain supreme guidance." Any political agreement creates gaps in the rule of law and leads to a lack of accountability. Nestlé shareholders should also resolve the issue of Nestlé's non-compliance with corporate principles and initiate a public debate in their home country, Switzerland.
(3) Since 2010 , the direct water withdrawal per ton of product has been reduced in every product category in order to achieve an overall reduction of 35\% [22]. To ensure continuous improvement in water efficiency, all factories use the "reduce, reuse and recycle" method. They continue to invest in innovative technologies and programs to reduce water consumption in their facilities and increase the efficiency of their processes. Since 2010, until the end of 2019, they have reduced the total water withdrawal per ton of product by $31 \%$ to 121 million cubic meters3 [22].

(4) Finally, Nestlé's failure to comply with the United Nations Global Compact and its commitment to human rights should lead to debates among members of the United Nations Global Compact, particularly members of its non-governmental organizations. Nestlé's method of challenging the Global Compact is based on the understanding that development and poverty reduction depend on prosperity and that prosperity can only come from efficient and profitable business. This has to be discussed by other members of the Global Compact.

\subsection{Mondelēz International's Profile}

Mondelēz International Inc. (MDLZ) is a large manufacturing and marketing company that offers a wide variety of beverage products and snacks. The company was founded in 2012 when Kraft Foods was restructuring its business to implement "highgrowth global snacks". Mondelēz International (Inc.) is the world's largest country for snacks with a net income of around 26 billion US dollars in 2019. Mondelēz International creates delicious happy hours in more than 150 countries / regions. The company is a global leader in chocolate, biscuits, chewing gum, candy and powdered drinks with billion-dollar brands such as OREO, belVita and LU biscuits, Cadbury Milk, Milka and Toblerone chocolate, children's sour candy and trident chewing gum. Mendel International is a proud member of the Standard \& Poor's 500 Index, the Nasdaq 100 Index and the Dow Jones Sustainability Index [23].

\subsubsection{Mondelēz International's CSR Policies and Reporting}

At Mondelēz International, they started the "Call for Wellbeing" campaign and asked themselves, suppliers and partners to work together to have a positive impact on the well-being of the world [24]. For Mondelēz International, sustainable development is part of its "Call to Well-being", a series of coordinated actions that support one of its five global strategies: "Protecting the Wellbeing of Our Planet and Its People" on the well-being of the world the four areas that are critical and have the greatest impact: snacks, sustainability, 


\section{International Journal of Engineering Applied Sciences and Technology, 2021 \\ Vol. 5, Issue 9, ISSN No. 2455-2143, Pages 30-43 \\ Published Online January 2021 in IJEAST (http://www.ijeast.com)}

community and safety. Water is the focus of their sustainable development strategy [23].

The MDLZ's water awareness and management plan covers all locations in areas that are currently under water stress or are expected to be under water stress soon (i.e., by 2025 according to WBCSD). They use WBCSD tools to produce water usage and water stress maps each year and will develop plans to focus their activities on those crops that are most consuming (current and forecast) in the most polluted areas. They continue to implement water management plans in many factories in areas of water scarcity, and all new factories must also incorporate water-efficient design principles, especially when water risk management is a priority. When they used the WBCSD Global Water Resources Tool to draw water and water pressure maps, they started using the new WRI Aqueduct Water Risk Map tool in 2013 to draw their entire water risk map [23]. Their study of the water footprint in the corporate life cycle also examined the potential harm to human health and ecosystems caused by freshwater consumption and water degradation.

\subsubsection{Mondelēz International's Conflicts}

Non-recyclable packaging has stepped up the work of postconsumer packaging, which is already difficult to recycle. In the United States, only $14 \%$ of plastic packaging from popular Mondelēz International brands (such as Oreo and Chips Ahoy) is recycled and increasingly flexible film or other nonrecyclable plastic packaging is being used [23]. If there are recyclable alternatives, using non-recyclable packaging wastes valuable resources that can be recycled multiple times. Consumer packaging like Mondelez has created major problems both post-consumer and downstream. Plastic packaging is a major component of cyclone pollution of the oceans, threatening marine animals and potential human health. Recent studies estimate that 8 million tons of plastic are thrown into the ocean every year and predict that by 2050 there will be more plastic in the ocean than fish. This has led the government to ban certain forms of plastic packaging. A report by the United Nations Environment Program estimated that the company's use of plastic materials caused environmental damage of \$ 115 million each year [23].

\subsubsection{The Ocean Pollution Threat}

Americans lose more material than any other country - 4 pounds per person per day. Paper and packaging materials represent the largest category of municipal waste at around $44 \%$. Almost only half of these materials are recycled and reused, but the fastest growing packaging material has a particularly low recycling rate of only 14\% [23]. As the US pushes for more packaging to be recycled, companies like Mondelēz are working harder to unnecessarily release non- recyclable packaging when there are readily available recyclable alternatives.

Iconic Mondelēz brands such as Oreo and Chips Ahoy are increasingly using flexible film or other non-recyclable plastic packaging (such as bags). Instead, billions of garbage packaging papers and small bags that represent a large amount of embedded energy are burned or buried in landfills or in the ocean. These products can be made from recyclable fiber or plastic packaging materials that are approved in most roadside recycling systems [23]. Giant swirling plastic particles have been found in five ocean regions (North and South Pacific, North India and South Atlantic). Researchers estimate that 150 million tons of plastic circulate in the gyrotron and spread over the sea surface of about 16 million square kilometers, which is roughly the sum of the United States and Australia [23].

A study published in Science in 2015 concluded that the loading speed of plastics in the ocean has exceeded previous expectations, increasing by 8 million tons per year (the equivalent of one garbage truck per minute). At this rate, the weight of plastic can exceed that of fish by 2050 if there is no significant relief [25]. A recent report from the Ocean Conservation Association concluded that poorly designed waste disposal systems (not just beach litter, sewage, or blown plastics) are a major contributor to marine plastics, especially in developing markets. The report estimates that by using only plastic materials, Mondelez will incur annual natural capital costs of US \$ 115 million, including the use of non-recyclable plastic packaging.

2.4.3 Mondelēz International's CSR Policies Post-Conflicts Mondelēz International aims to reduce absolute water consumption at priority production sites with scarce water resources by $10 \%$. In 2018, they completed the disposal of single-use water at their Canadian facility in Gladstone, reducing water use by $29 \%$ - an overall reduction of $69 \%$ since 2014. In Peru, a project to reuse treated wastewater at its Lima facility reduced water use by 2,400 cubic meters per year [23]. Meet or exceed the requirements of all applicable environmental laws and regulations. Therefore, Mondelēz International expects all employees to carry out their work in accordance with this policy and to report any environmental concerns to management. Sustainability goals for solving environmental problems:

(1) Eliminate 65,000 tons of packaging without causing food waste. Encourage packaging innovation, treat plastic waste in a $100 \%$ recyclable packaging method and include recycling information [24]. Mondelēz International announced a new commitment to make all packaging materials recyclable and provide recycling information by 2025 . The company will work together so that packaging materials can be 


\section{International Journal of Engineering Applied Sciences and Technology, 2021 \\ Vol. 5, Issue 9, ISSN No. 2455-2143, Pages 30-43 \\ Published Online January 2021 in IJEAST (http://www.ijeast.com)}

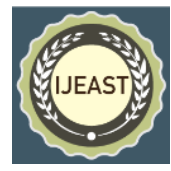

collected and recycled in markets around the world. This new commitment is part of the company's strategy to achieve a circular economy for packaging and will help realize its long-term vision of zero net waste packaging. The company's strategy is to achieve its long-term vision of zero net waste packaging by achieving two goals: making it easier for consumers to recycle packaging and supporting industry alliances to increase recycling rates. Recycling information will be made available to consumers by 2025 . Given the large number of local recycling systems around the world, the company will endeavor to make it easier for consumers to recycle or reuse product packaging after use. The company will support industry alliances and publicprivate partnerships in the development of a critical waste management infrastructure to reduce waste and increase actual recycling rates.

(2) Reduce priority water use in areas of severe water scarcity by $10 \%$. The company's water footprint assessment uses a life cycle approach to assess water use and its impact on human health and ecosystems, from the supply chain to direct operations to consumer use and waste disposal. They have participated in various programs to address various water risks in their agricultural supply chain. They also used the WBCSD definition of water scarcity to estimate the water pressure factor for each operation. At the same time, the WRI aqueduct is used to map the water risks of its facilities, including physical risks (quality and quantity), regulatory risks and dual risks. All business areas / regions have annual water saving targets. Keep a full track of water and wastewater in the manufacturing database every month. They have set a company-wide water intensity target that is to reduce manufacturing water intensity by $15 \%$ from 2010 to 2015 [23].

\section{RESUlTS \& DisCUSSION}

Businesses can play an important role in managing water resources. Effective water management is socially responsible behavior. However, tremendous economic benefits can also be achieved by identifying water risks and business opportunities. This section compares the company's response to the conflicts examined and whether such conflicts have influenced corporate social responsibility policies. In order to compare corporate social responsibility policies of companies, it is important to recognize the differences between the four companies. The parent companies of Coca-Cola, PepsiCo and Mondelēz International are in the US, and Nestlé in Switzerland. Because the parent company is located in different countries, different legal systems and jurisdictions apply. However, these multinational corporations are publicly traded on NASDAQ (Mondelēz International and PepsiCo), the New York Stock Exchange NYSE (Coca-Cola), and Southwest Securities SWX (Nestlé).

As the Coca-Cola case study shows, the company has been slow to respond to the conflict in India. The company's first response was limited to proving that certain allegations against the company were false. As a result, Coca-Cola's strategy is focused on building an honest corporate image and regaining consumer confidence by, for example, resolving conflicts and proving its position in the company's 2006 Corporate Responsibility Review. The consequences of this are too severe to be resolved through explanations or attempts to make the conflict transparent. Although some of Coca-Cola's actions did not result in violations of Indian laws (e.g., claims that Coca-Cola's beverages contained illegal amounts of pesticides), the loss of reputation was worrying. Losing the opportunity to enter such an important market, hurt its reputation, and hurt the company's business in other regions (e.g., at various university campuses in the US) would be beyond implementing a comprehensive corporate social responsibility policy Companies (e.g., the implementation of) goes beyond) the cost of.

Analysis of the PepsiCo case study clearly showed that the company was slow and steady in responding to the Indian conflict. Additionally, the main reason for this situation is that social and regulatory changes in several regions of India have affected the company's ability to resolve conflicts. In recent years, increasing pressure on water resources in the Indian states of Tamil Nadu and Kerala has led to local opposition to multinational companies and product boycotts. In 2018, Pepsi India has 10 high water risk facilities, most of which rely on a single water source that relies on annual rainfall and becomes increasingly stressful in drought conditions. A detailed water vulnerability assessment was carried out for each location in order to better understand the company's risks and opportunities.

PepsiCo's response in these catchment areas is to implement its global water strategy and seek a positive water impact inside and outside of its communities. This means that the company's efforts and cooperation are aimed at long-term, sustainable continuous water security. Others are dependent on the water supply. Implement this global strategy by focusing on water catchment management, maintaining water on farms, reducing water use in the agricultural supply chain, promoting access to water and advocating strong water policies in the community. Therefore, PepsiCo is currently implementing this strategy in India. For example, they actively complement the high-water risk pools in which they operate. In 2018, we replenished more than 2.7 billion liters of water in India through community programs such as rainwater harvesting, reservoir restoration and dam inspection. Not only 


\section{International Journal of Engineering Applied Sciences and Technology, 2021 \\ Vol. 5, Issue 9, ISSN No. 2455-2143, Pages 30-43 \\ Published Online January 2021 in IJEAST (http://www.ijeast.com)}

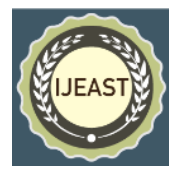

can these efforts reduce water risk, but they can also improve PepsiCo's reputation.

Other companies like Nestlé can't solve the water problem far from there, but they can help, both directly and indirectly, with water management. Nestlé Drinking Water tracks its factories and spring performance to focus investments in the most important and impactful places. The amount of "pure life" produced by Nestlé and the associated groundwater harvesting apparently exceeds the amount of renewable energy and is therefore considered unsustainable. While this statement contradicts Nestlé's own Corporate Business Principles, it only raises certain human rights concerns and does not automatically constitute such violations. All in all, I have to say that Nestlé's "clean life" in Pakistan is for the vast majority of people who don't Having access to safe drinking water is not an affordable option. On the contrary, the introduction of bottled water in Pakistan is an attempt at the culture of bottled water. In the culture of bottled water, water is a status symbol and a lifestyle of the wealthy. However, Nestlé's market strategy goes against its commitment to human rights and sustainable development, which is vital from an ethical standpoint. Regardless of Pakistani water regulations, it is important that Nestlé's drinking water manages its resources sustainably, monitoring water consumption and water levels.

Mondelēz International has made significant strides by continuously improving packaging design to minimize the impact of packaging on the environment. Most of the company's packaging has been recycled, recyclable, or recyclable. Around $75 \%$ of packaging is made of glass, paper or metal, while around $70 \%$ of paper-based packaging is made from renewable raw materials. The company has made significant strides towards its packaging recyclability targets, removing 65,000 tons of packaging from its product portfolio between 2013 and 2020 [246]. It is on the right track to meet its 2025 goal: $100 \%$ packaging that is recyclable is designed to be recyclable. All paper and cardboard used by Mondelēz International, as well as some hard and soft plastic films, are recyclable. In addition, all fiber packaging used to store, transport and display the products worldwide comes from sustainable resources, regardless of whether they are certified recyclable or deforestation-free.

While some of Mondelēz's recycling goals are relatively easy to achieve, especially cardboard boxes, it can be more difficult to put cookies and other containers in recyclable packaging. In recent years, the company has come under pressure from a radical organization called As You Sow to phase out plastic packaging. The organization has made an annual proposal to shareholders pushing for change. In addition to promoting these changes through marketing and promotional campaigns, Mondelēz wants to make it clear on the product label that the packaging is fully recyclable and give consumers some practical tips on how to help when the packaging is empty. Compared to competitors, this can give the company a boost to sustainable development and show consumers that they are talking more than just sustainability.

The case study shows that the company's corporate social responsibility policy changed after the conflict. Today CocaCola has implemented various initiatives to solve India's water problems, including research, partnerships with Indian local governments and international organizations, and community projects. In addition, the company didn't stop there. Water management is one of the core elements of Coca-Cola's global corporate social responsibility policy. The company strives to achieve the goals of water management efficiency. Coca-Cola does not recognize that the conflict in India is the main motivation for an ambitious water management policy. Given the serious damage to its image and the resulting loss of income, the conflict in India may have influenced the company's decision to implement a corporate social responsibility guideline on the efficiency of water management in its global operations. In addition, Coca-Cola has improved its reporting activities by updating the latest developments in the GRI guidelines.

While PepsiCo has received many criticisms in its long history, PepsiCo has recognized the importance of social responsibility to its reputation. Therefore, PepsiCo continues to emphasize its commitment to sustainable growth through corporate social responsibility and is committed to generating healthy financial returns while giving back to the communities it serves. The company's social responsibility motto is "Performance with purpose". As it achieves business and financial success, it makes positive marks on society. PepsiCo addresses the concerns of governments at all levels, as well as non-governmental organizations and individual Indians. PepsiCo's response in these pools is to implement its global water strategy and achieve positive water impacts in and around its work communities. This means that their efforts and collaboration will be aimed at achieving long-term benefits for their businesses and other organizations on water security that depends on the water supply. Implement this global strategy by focusing on water catchment management, maintaining water on farms, reducing water use in the agricultural supply chain, promoting access to water and advocating strong water policies in the community. They are now implementing this strategy in India. For example, they actively complement the high-water risk pools in which they operate. In 2018, they replenished more than 2.7 billion liters of water in India through community programs such as rainwater harvesting, reservoir repair and dam inspection. Not only can these efforts reduce water risk, but they can also improve Pepsi's reputation. In addition, as a Coca-Cola company, Pepsi has improved its reporting activities by updating the latest developments in the GRI guidelines. The targeted performance demonstrates Pepsi-Cola India's belief that its 


\section{International Journal of Engineering Applied Sciences and Technology, 2021 \\ Vol. 5, Issue 9, ISSN No. 2455-2143, Pages 30-43 \\ Published Online January 2021 in IJEAST (http://www.ijeast.com)}

business is inherently connected to the surrounding community and the world.

\section{CONCLUSION}

This article describes the role of businesses in freshwater today. The aim of this study is to examine the role of four companies (Coca-Cola, Pepsi, Nestlé, and Mondelēz International) in relation to freshwater. Accountability studies have shown that in terms of the company's water impact, it is difficult to determine where corporate responsibility begins. This article presents four case studies of the Corporate Social Responsibility Guidelines from Coca-Cola, Pepsi, Nestlé, Mondelēz and International. These multinational companies are involved in environmental conflicts. This article examines conflicts, the actions the company is taking to resolve them, and the CSR policies related to those conflicts. This article aims to answer the fool's question, "Will the conflict affect the company's CSR policy?"

Overall, the authors found that the five multinational companies analyzed had implemented basic corporate social responsibility guidelines before experiencing the conflicts studied. Coca-Cola took early steps to report on the company's 2001 activities. Another early implementer of the Corporate Social Responsibility guidelines was Nestlé (Nestlé) in 2001. PepsiCo has published its Annual Supplier Responsibility Progress Report on its website since 2006. Mondelez International announced the social responsibility of its global business plan on its official website in 2013.

The conflict between the two companies like Coca-Cola, PepsiCo, Mondelez International, and Nestlé resulted in different levels of water pollution. These issues have resulted in a bad reputation for the company. The Coca-Cola conflict in India includes allegations of water pollution and excessive abstraction of groundwater, as well as allegations of high levels of pesticide residues in Coca-Cola beverages made in the country. Media attention to the conflict is so widespread that the negative impact on the company's image is not limited to India, but is spreading to the US as well. In addition, this conflict has adversely affected the company economically and reduced sales and earnings losses. Big plastic polluters like The Coca-Cola Company, Nestlé and PepsiCo have made little progress in reducing the total amount of plastic or switching to reusable packaging. According to a recent report by Ellen MacArthur, the signatories of the Global Commitment to the New Plastics Economy reduced the use of virgin plastic by $0.1 \%$ from 2018 to 2019 . Coca-Cola actually increased the amount of plastic used. Not only have the most polluting companies failed to keep their already weak promises, they are increasingly turning to green environmental protection to achieve sustainable development of the export-oriented maritime market while continuing to "delay, dissipate and destroy" real progress.
Mondelēz International's well-known brands (such as Oreo and Chips Ahoy) are increasingly being packaged in soft film or other plastic packaging (such as bags) that are not recyclable. Billions of packaging waste and bags, which represent a large amount of embedded energy, are burned or buried in landfills or in the ocean. The world's oceans have blocked waterways, destroyed marine ecosystems and destroyed the marine food web. Giant swirling plastic particles have been found in five ocean regions (North and South Pacific, North India and South Atlantic). Researchers estimate that 150 million tons of plastic circulate in the gyrotron and spread over the sea surface of about 16 million square kilometers, which is roughly the sum of the United States and Australia.

Multinational corporations respond to conflicts in a variety of ways, from trying to repair reputational damage and rejecting claims to remedying them. Coca-Cola's original approach was to deny that the claims were true. The company is very open to this and uses the media, website and reports to make statements setting out its position on the conflict. For example, Coca-Cola responded to news reports and issued public statements and included the latest news on the conflict in India in the India Sustainability Report and its website. However, the primary purpose of this effort is to restore the integrity of the company by demonstrating that the allegations are not true. However, as the case study shows, public statements and reports of conflict are not enough for the company to repair its reputational damage and regain the trust of Indian customers. In response, the company took a more proactive approach to repairing and preventing damage to India's water resources.

PepsiCo continues to sell soft drinks with dangerously high levels of pesticides in India - even three years after the Indian government confirmed that these products were dangerous. In recent years, increasing pressure on water resources in the Indian states of Tamil Nadu and Kerala has led to local opposition to multinational companies and product boycotts. In 2018, Pepsi India has 10 high water risk facilities, most of which rely on a single water source that relies on annual rainfall and becomes increasingly stressful in drought conditions. In the end, Pepsi-Cola decided to provide a remedy and solution instead of just ignoring and providing public statements and sustainability reports. Pepsi-Cola has published the India Sustainability Report and posted the latest news about the conflict in India on its website. Implement this global strategy by focusing on water catchment management, maintaining water on farms, reducing water use in the agricultural supply chain, promoting access to water and advocating strong water policies in the community. Not only can these efforts reduce water risk, but they can also improve PepsiCo's reputation. 


\section{International Journal of Engineering Applied Sciences and Technology, 2021 \\ Vol. 5, Issue 9, ISSN No. 2455-2143, Pages 30-43 \\ Published Online January 2021 in IJEAST (http://www.ijeast.com)}

The associated groundwater abstraction obviously exceeds the amount of renewable energy, which has an impact on Nestlé's reputation. Although Nestlé has solved the problem of reputational damage. Nestlé always works in accordance with local regulations and requirements. Nestlé Waters is independent of Pakistani water laws and has started to manage resources in a sustainable way, while monitoring water use and levels. So widespread media attention to the conflict is that the negative impact on the company's image is not limited to Pakistan. In addition, this conflict has adversely affected the company economically and reduced sales and earnings losses. The company is very open to this and uses the media, websites and reports to provide statements explaining its position in the conflict. For example, Nestlé made a public statement and included the latest news on the conflict in Pakistan in its sustainability report on Pakistan and its website.

The management of Mondelez International has not yet provided any information on the guidelines to maximize the recyclability of its packaging or a growing response policy for plastic packaging in the ocean ring and the combination of plastic packaging in the ocean ring in relation to marine animals and potential data related to threats to human health. Shocking new data suggests that the weight of plastic spilled into the ocean from consumer products like Mondelez could exceed fish content by 2050 . The company reduced the weight of the packaging, but a recent report found that lightweight construction can have an unexpected impact on the value of plastics. Associating Mondelez branded products with waste packaging and toxic marine pollution could put the company's brand at risk. The company does not disclose any plans or targets for the disposal of non-recyclable packaging.

The case study provides evidence that multinational companies changed their CSR policies after a conflict. The common characteristic of the policy changes from Coca-Cola, Pepsi, and Nestlé is that they set specific goals to achieve the goals at the company level. While Mondelez International has not set any specific goals, it has committed to changing its supplier responsibility practices. In addition, the sustainability report of the corporate social responsibility guidelines of the five multinational companies is a long-term commitment, not just to resolve current conflicts.

Perhaps Coca-Cola is arguably the company that adopted one of the most ambitious corporate social responsibility guidelines after the Indian conflict. Coca-Cola appears determined to address its environmental impact, especially water operations. Given the nature of the impact, the company can research and take action to prevent and repair the damage. The results are measurable. Coca-Cola has made such an effort by taking steps to address the water problems caused in India and improve the image of customers. These initiatives include research and partnerships with Indian local governments. As a result, Coca-Cola made water management a core element of its global corporate social responsibility policy, and the company has committed to achieving quantifiable goals for water management efficiency. CocaCola does not recognize the conflict in India as the main motivation for a water policy. However, given the serious damage to its reputation and the resulting loss of revenue, the conflict in India is likely to influence the company's decision to implement corporate social responsibility guidelines with regard to the efficiency of water management in its global operations.

The negative publicity eventually led PepsiCo to set new standards for water management. While PepsiCo has received many criticisms in its long history, PepsiCo has recognized the importance of social responsibility to its reputation. PepsiCo continues to emphasize its commitment to sustainable growth through corporate social responsibility and is committed to generating healthy financial returns while giving back to the communities it serves.

Mondelēz International announced a new commitment to make all packaging materials recyclable and provide recycling information by 2025 . However, the company did not provide any information on plans or targets for phasing out nonrecyclable packaging, nor on how to deal with the growing plastic packaging. In the ocean. For Mondelēz International, sustainable development is part of its "Call to Wellbeing", a series of coordinated actions that support one of its five global strategies: "Protect the well-being of our planet and its people." Assessment Use life cycle methods to assess water use and its impact on human health and ecosystems, from supply chain to direct operations to consumer use and waste disposal. Finally, Nestlé has also updated its water pollution policy. Therefore, it is the company's responsibility to create value for the stakeholders and to enrich nature. This concept is called Shared Value Creation. Nestlé usually works hard to create a common value that includes the following international laws and country / region codes with corporate principles. Nestlé is committed to creating value for food, water and rural development.

In summary, the four case studies from Coca-Cola, PepsiCo, Nestlé, and Mondelez International show that multinational corporations changed their corporate social responsibility and reporting policies after the conflict. These companies resolve these conflicts publicly through the media or in their annual or sustainability reports, thereby making these conflicts transparent. Coca-Cola, Mondelez International and PepsiCo have taken a proactive stance and taken proactive measures to address the water problem. Nestlé has a responsibility to coexist by creating value for stakeholders and enriching nature. Time will only tell if we will stick to our commitment to change supplier responsibility practices. This article argues that companies should take responsibility for the effects of water resources, especially when their effects affect water scarcity and / or public water use in areas with weak governments. Interestingly, the company's research on 


\section{International Journal of Engineering Applied Sciences and Technology, 2021 \\ Vol. 5, Issue 9, ISSN No. 2455-2143, Pages 30-43 \\ Published Online January 2021 in IJEAST (http://www.ijeast.com)}

sustainable water use, environmentally friendly products, and environmentally friendly production methods is evolving.

\section{REFERENCE}

[1] CDP. (2020). Water Program. https://www.cdp.net/water.

[2] World Water Assessment Programme (WWAP). (2019). The United Nations World Water Development Report 2019: Leaving No One Behind. Paris, UNESCO.

[3] World Water Assessment Programme (WWAP). 2017. Migration and its Interdependencies with Water Scarcity, Gender and Youth Employment. Paris, UNESCO.

[4] UNESCO. (2020). Water for People, Water for Life, United Nations World Water Development Report. https://en.unesco.org/about-us/unesco-house,

[5] Mekonnen, M.M., Hoekstra, A.Y., Neale, C.M.U., Ray, C., and Yang, H.S. (2020). Water productivity benchmarks: The case of maize and soybean in Nebraska. Agric. Water Manage., vol. 234, pp. 106-122.

[6] WHO. (2020). The Global annual assessment of sanitation and drinking water (GLAAS) and WHO, fact files on water.

https://www.who.int/features/factfiles/\%20water/waterfac ts/en/index $2 . h t m l$

[7] Break Free from Plastic. (2021). Brand Audit 2020. Branded Vol.3: Demanding Corporate Accountability for Plastic Pollution.

http://www.breakfreefromplastic.org/wpcontent/uploads/2020/12/BFFP-2020-Brand-AuditReport.pdf

[8] The Coca-Cola Company. (2020). UN Global Compact. http://www.thecocacolacompany.com/citizenship/un_glob al_compact.html

[9] The Coca-Cola Company. (2020). Improving Water Efficiency.https://www.coca-cola company.com/company

[10] The Coca-Cola Company. (2019). Sustainability Report: Reasons to Believe. http://www.thecocacolacompany.com/sustainabilityreport /TCCC20102011SustainabilityReport_Full.pdf

[11] Banerjee, T. (2010). Right to Water: Some Theoretical Issues. Contemporary Issues and Ideas in Social Sciences.

[12] Business Inquirer. (2020). Coca-Cola PH partners with Plastic Bank to stop Ocean Plastic. https://business.inquirer.net/306576/coca-cola-phpartners-with-plastic-bank-to-stop-ocean-plastic

[13] Pirson, M., and Malhotra, D. (2008). Unconventional Insights for Managing Stakeholder Trust Working Paper, Kennedy School of Government, pp. 9-10.

[14] Laville, S. (2019). Coca-Cola admits it produces $3 \mathrm{~m}$ tones of plastic packaging a year. The Guardian. https://www.theguardian.com/business/2019/mar/14/coca cola-admits-it-produces -3m-tonnes-of-plastic-packaginga-year

[15] Chalabi, M. (2019). Coca-Cola is world's biggest plastic polluter again. The Guardian. https://www.theguardian.com/news/datablog/2019/nov/09 /coca-cola-world-biggest-plastics-polluter-again-datablog

[16] PepsiCo. (2021). Water Security 2019. https://www.pepsico.com/docs/album/esg-

topicspolicies/2019-cdp-waterresponse.pdf?sfvrsn $=\mathrm{d} 876763 \mathrm{f} 4$

[17] Greenpeace. (2020). Reusables can be used safely: Over 125 health experts fire back at the plastic industry. https://www.greenpeace.org/africa/en/blogs/11438/reusab les-can-be-used-safely-over-125-health-experts-fire-backat-the-plastic-industryl,

[18] PepsiCo. (2019). Sustainability report goals and progress. https://www.pepsico.com/sustainability/goals-andprogress.

[19] Levi, B.G. (2008). Trends in the hydrology of the western US bear the imprint of manmade climate change. Physics Today, 61(4), 16-18.

[20] Fresner, J., and Engelhardt, G. (2004). Experiences with integrated management systems for two small companies in Austria. J. Clean. Prod, 12, 623-631.

[21] Nestlé. (2021). Creating shared value and meeting our commitments 2019: Progress report. https://www.nestle.com/sites/default/files/202101/creating-shared-value-report-2019-en.pdf

[22] Nestlé. (2021). Nestle creates market for food-grade recycled plastics, launches fund to boost packaging innovation," https://www.nestle.co.uk/en$\mathrm{gb} / \mathrm{media} /$ pressreleases/allpressreleases/nestle -createsmarket-food-grade-recycled-plastics-launches-fund-boost

[23] Mondelez International Inc. (2020). CDP Water Security Questionnaire 2020 https://www.mondelezinternational.com//media/Mondelez /Snacking-Made-Right/ImpactReporting/ Measuring-OurProgress/AdditionalResources2/SUBMITTED_Mondelez International_ 4Inc__CDP_Water_Security_Questionnaire_2020.pdf

[24] Mondelēz International Inc. (2019). Mondelēz International Snacking Made Right 2019 Summary Report. $\quad$ https://www.mondelezinternational.com//media/Mondelez/Snacking-Made-Right/SMRReport/2019_MDLZ_Snacking_Made_Right_Summary.p $\underline{\mathrm{df}}$

[25] Williams, M., Gower, R., Green, J., Whitebread, E., Lenkiewicz, Z., and Schröder, P. No Time to Waste: Tackling the Plastic Pollution Crisis Before It is Too Late, London: Tearfund. https://opendocs.ids.ac.uk/opendocs/handle/20.500.12413 $\underline{14490}$ 